\title{
Clinical Values of Orally Administrated Gastrografin in Management of Adhesive Small Bowel Obstruction
}

\author{
SAMY OSMAN, M.D.; HANY ABD EL-KAREEM, M.D.; MOHAMED YAHYA, M.D. and \\ AHMED SALAH, M.Sc.
}

The Department of General Surgery, Faculty of Medicine, Assiut University Hospital, Assiut, Egypt

\begin{abstract}
Background: Adhesive Small Bowel Obstruction (ASBO) is the most common cause of small bowel obstruction. Patients with ASBO are difficult to evaluate and to manage and their treatment is still controversial. Diagnostic and therapeutic benefits of oral gastrografin in management of patients with ASBO are investigated by several studies, but there is no consensus.
\end{abstract}

Aim of the Study: The aim of the study was to assess the diagnostic and therapeutic roles in the management of ASBO of gastrografin in cases of ASBO.

Material and Methods: A total of 80 patients diagnosed as ASBO were included in this study. Patients were randomized into control and gastrografin groups. In the gastrografin group $100 \mathrm{~mL}$ of gastrografin was administered through a nasogastric tube followed by serial abdominal radiographs. Patients in whom the contrast failed to reach large bowel within $24 \mathrm{~h}$ were considered to have complete obstruction and laparotomy was performed. Patients in whom gastrografin reach in the colon within $24 \mathrm{~h}$ after dye administration were considered as partially obstructed, and conservative treatment was continued. The patients were operated on if signs of strangulation were developed or they failed to improve within $48 \mathrm{~h}$.

Results: Out of forty patients with ASBO received oral gastrografin, six patients required surgical intervention with operative rate of $15 \%$ in control group. Four-teen out of forty patients treated with the traditional conservative treatment required surgical intervention with operative rate of $35 \%$ in control group. Hospital stay was shorter in gastrografin group (3.2 days), than in control group (5.3 days).

Conclusion: The use of gastrografin in ASBO reduces the surgical rate, resolution time and the hospital stay.

Key Words: Gastrografin - ASBO-Adhesions - Bowel obstruction - Non-operative management.

\section{Introduction}

ADHESIVE Small Bowel Obstruction (ASBO) is the most common complication after abdominal surgery, [1] being responsible for $60 \%$ to $70 \%$ of

Correspondence to: Dr. Ahmed Salah Ahmed, E-Mail: ahmedgado777@yahoo.com small bowel obstruction [2]. The rate of adhesions is estimated around $94 \%-95 \%$ after abdominal surgery. Recently it has been reported that this rate is much lower in laparoscopic procedures, although the exact percentage is not known [3]

In 2013, the World Society of Emergency Surgery suggested two distinct approaches for the management of acute ASBO [4]. Non-operative management, when there are no signs of strangulation or peritonitis or history of persistent vomiting or combination of computed tomography signs (free fluid, mesenteric edema, lack of feces signs, devascularized bowel), whereas operative management should be considered if the patient presented with signs of strangulation or peritonitis, also at any time during non-operative management if signs of strangulation or peritonitis are developed [4]

Indication and length of non-operative treatment and appropriate timing for surgery may represent an insidious issue, as the delay in surgical treatment may cause a substantial increase of morbidity and mortality [5]. However repeated laparotomy and adhesiolysis may worsen the process of adhesion formation and their severity $[6,7]$.

Gastrografin has been reported to have a therapeutic effect and to predict the need for early surgical intervention in ASBO [8]. In addition, gastrografin reduces the operative rate and length of hospital stay [9]. However, these findings are still conflicting, as some authors denied any therapeutic advantages [10]

Several meta-analyses Abbas, [7], Branco, [3], and Di Saverio, [4], have been published with conflicting results: The role of WSCA in reducing

\section{Abbreviations:}

ASBO: Adhesive Small Bowel Obstruction. 
the need for surgery is not clear, with significant results reported only by the most recent review [11-13].

Therefor this study was designed to detect the diagnostic and therapeutic role of oral gastrografin in management of ASBO.

\section{Aim of the study:}

The aim of the study was to:

Determine the reliability of gastrografin and serial abdominal radiographs in predicting the success of conservative treatment in patients admitted with adhesive small bowel obstruction, and its efficacy and safety in reducing the need for surgical intervention and reducing hospital stay in patients with ASBO.

\section{Material and Methods}

This was a prospective randomized study in which 80 patients with ASBO were included. They were admitted between March 2016 and June 2017 at the General Surgery Department, Assuit University Hospital, Egypt. The diagnosis was based on a history of single or multiple previous abdominal surgery, confirmatory clinical signs and symptoms (abdominal pain, vomiting, distension, and constipation), and supporting radiological evidence (abdominal radiograph or computed tomography scan). An abdominal CT with intravenous contrast was performed in some cases in order to rule out other reasons of small bowel obstruction.

Inclusion criteria include: Patient with history of previous single or multiple abdominal operations with clinical and radiological pictures of intestinal obstruction, without signs of strangulation or peritonitis.

Exclusion criteria include: Patients with suspicion of strangulation or peritonitis, pediatric age group less than $18 \mathrm{y}$, patients with history of abdominal radiotherapy, large bowel obstruction, active inflammatory bowel disease, recent (within 4 wk.) abdominal surgery, and all patients in whom the final diagnosis was not ASBO.

The study was approved by the Ethics Committee of the Faculty of Medicine, Assiut University. All the patients were informed about the methods and the possible complications of the procedure, and a written consent was obtained.

All the patients were evaluated by complete history taking, complete clinical examination, radiological evaluation, and complete laboratory evaluation. They were all treated initially with nasogastric decompression, IV fluids, with correction of acid base imbalance. Patients included in the study were randomized by closed envelope method into:

Control group: In this group 40 patients were included, and the small bowel obstruction was considered partial if there was gas in the colon; if absent, the obstruction was defined as complete. Patients were evaluated at $24 \mathrm{~h}$ for presence of clinical and radiologic signs of mechanical obstruction. Surgical exploration was done for those patients with findings of complete mechanical obstruction. The others who showed gases in the colon after $24 \mathrm{~h}$ and early clinical and radiological relief, of bowel obstruction were fed and discharged if tolerating oral feeding. But if the patients showed no clinical and radiologic improvement in the first $24 \mathrm{~h}$, clinical and radiologic re-evaluations were done at $48 \mathrm{~h}$. If they showed persistent or worsening signs of obstruction, laparotomy was performed. Otherwise, they were fed and discharged after tolerating diet.

Gastrografin group:In this group 40 patients were included, $2 \mathrm{~h}$ after insertion of the nasogastric tube with complete suction of the gastric fluid, good hydration; $100 \mathrm{~mL}$ of the dye was administered via a nasogastric tube, then clamped for $2 \mathrm{~h}$. Abdominal plain films were repeated at 8 and $24 \mathrm{~h}$ intervals. Patients in whom abdominal radiography with gastrografin failed to reach the colon after $24 \mathrm{~h}$ were diagnosed as complete ASBO, and patients who had complete obstruction were subjected to surgical exploration.

Patients with contrast medium in the colon within $24 \mathrm{~h}$ of the dye being administered were considered to have partial SBO, and were fed, and discharged if tolerating oral diet. Patients not yet relieved of obstruction continued conservative treatment. Forty-eight hours from gastrografin ingestion, patients with persistent obstruction were submitted to surgery. The other patients showing a later clinical improvement within $48 \mathrm{~h}$ were fed and discharged.

Patient's data included demographic data, duration of symptoms before admission to hospital, and previous surgical operations. Previous episodes of bowel obstruction, operative finding in patients subjected to surgery, and time until resolution of symptoms were recorded and analyzed.

\section{Sample size:}

A sample size of 80 patients was calculated using an online statistical calculator which utilized 
the estimation method for a sample size for continuous outcome superiority trial. The primary outcomes were the length of hospital stay, the time to resolution of clinical signs and symptoms, and efficacy in predicting failure of conservative management and the need for surgical intervention, and its role in decreasing the operative rate in cases of ASBO.

\section{Statistical analysis:}

The findings were analyzed using SPSS Version 10.0 (SPSS Inc., Chicago IL). Values were expressed as mean $\pm \mathrm{SD}$. The Chi square test was used to analyze categorical variables. Student's unpaired $t$-test was used to compare statistical significance of numerical variables. $p$-value less than 0.05 was considered as statistically significant.

\section{Results}

This study includes 80 patients, admitted to General Surgery Department at Assiut University Hospital and diagnosed as adhesive small bowel obstruction without signs of strangulation or peritonitis at time of admission between March 2016 till June 2017, and diagnosed as adhesive intestinal obstruction. These patients were randomized into two groups:

Control group: Included 40 patients, 23 (57.5\%) males and $17(43.5 \%)$ females with a mean age of $45.6 \pm 15 y$.

Gastrografin group:Included 40 patients, 25 $(62.5 \%)$ males and $15(37.5 \%)$ females with a mean age of $45 \pm 15.8$ ys.

Both groups were well matched for age, gender, number of previous surgeries, previous episodes, and duration of symptoms before admissions, as shown in the following (Table 1).

\section{Number of previous operation:}

Seventeen $(21.25 \%)$ patients had previously undergone multiple abdominal operations, whereas $63(78.75 \%)$ patients presented history of only one surgical operation as shown in (Table 2).

\section{Types of previous abdominal surgery:}

The types of previous operations were appendectomy in 20 patients (25\%), and gynecological operations in $19(23.75 \%)$ patients as shown in Fig. (1).

\section{Clinical presentation of the patients:}

Most common presentation is abdominal pain and vomiting as shown in Fig. (2).

\section{Outcome:}

In gastrografin group, obstruction resolved in $34(85 \%)$ patients after a mean time of $18.8 \mathrm{~h}$. Twenty-four $\mathrm{h}$ from administration of gastrografin, complete obstruction was observed in $5(12.5 \%)$ patients who were submitted to laparotomy (1 patient of them required bowel resection for strangulation), 35 (87.5\%) patients showed partial obstruction. Of 35 patients, only $1(2.1 \%)$ showed persistent radiologic and clinical obstruction after 48h, who was explored further, (Table 4).

In control group, after $24 \mathrm{~h}$ of conservative treatment, 8 of $40(20 \%)$ patients had complete mechanical obstruction clinically and radiologically (no gases in the colon), and these patients were submitted to laparotomy. On the other hand, 32 $(80 \%)$ patients were continued with conservative treatment, and $6(15 \%)$ of them required a laparotomy after $48 \mathrm{~h}$ follow-up due to persistent clinical and radiologic obstruction. The difference in the overall operative rate between both groups (15\% in gastrografin group versus $35 \%$ in control group) reached statistical significance, (Table 3 ).

\section{Time of resolution and hospital stay:}

Gastrografin shortens the duration of obstruction and hospital stay. The time from the hospital admission for obstruction to resolution of symptoms was significantly lower in gastrografin group (18.8 versus $41.5 \mathrm{~h}$ ). The length of hospital stay revealed a marked reduction in gastrografin group (3.9 versus 6.8d), (Table 4).

Operative predication for ASBO after administration of gastrografin:

Gastrografin shortens the duration of obstruction and hospital stay. The time from the hospital admission for obstruction to resolution of symptoms was significantly lower in gastrografin group (18.8 versus $41.5 \mathrm{~h}$ ). The length of hospital stay revealed a marked reduction in gastrografin group (3.9 versus $6.8 \mathrm{~d})$.

The sensitivity, specificity, PPV, and NPV for gastrografin follow through as an indicator for operative treatment of ASBO were calculated to be $83.3 \%, 100 \%, 100 \%$, and $97.41 \%$, respectively, (Table 5).

Neither gastrografin-related morbidity (including fluid and electrolytes disturbances, aspiration pneumonia, allergy, and shock) nor mortality was noted in this study. 
Table (1): Demographic data.

Table (2): Number of previous operation.

\begin{tabular}{|c|c|c|c|c|c|c|c|}
\hline & $\begin{array}{l}\text { Control } \\
\text { group }\end{array}$ & $\begin{array}{l}\text { Gastrografin } \\
\text { group }\end{array}$ & $\begin{array}{l}\text { Previous } \\
\text { surgery }\end{array}$ & $\begin{array}{l}\text { Control } \\
\text { group }\end{array}$ & $\begin{array}{l}\text { Gastrografin } \\
\text { group }\end{array}$ & Total & $\begin{array}{c}p- \\
\text { value }\end{array}$ \\
\hline - Males & $23(57.5 \%)$ & $25(62.5 \%)$ & - One & 32 & 31 & $63(78.75 \%)$ & \\
\hline - Females & $17(42.5)$ & $15(37.5 \%)$ & - Two & 7 & 9 & $16(20 \%)$ & \\
\hline - Age & $19-75$ ys & 21-71ys & - Three & 1 & 0 & $1(1.25 \%)$ & \\
\hline - Age mean & $45.6 \pm 15 y s$ & $45 \pm 15.8 \mathrm{ys}$ & - Multiple & 8 & 9 & $17(21.25 \%)$ & 0.724 \\
\hline $\begin{array}{l}\text { - Duration of symptoms before } \\
\text { admission (h) }\end{array}$ & $35.5 \pm 14.2$ & $38.4 \pm 12.3$ & $\begin{array}{l}\text { previous } \\
\text { surgery }\end{array}$ & & & & \\
\hline
\end{tabular}

Table (3): Outcome and operative rate.

\begin{tabular}{|c|c|c|c|c|c|}
\hline & \multicolumn{2}{|c|}{ Gastrografin group } & \multicolumn{2}{|c|}{ Control group } & \multirow[b]{2}{*}{$\begin{array}{c}p- \\
\text { value }\end{array}$} \\
\hline & $\begin{array}{l}\text { Gastrografin } \\
\text { reach colon } \\
\text { within } 24 \mathrm{~h} .\end{array}$ & $\begin{array}{c}\text { Gastrografin } \\
\text { did not reach } \\
\text { colon within } 24 \mathrm{~h} \text {. }\end{array}$ & $\begin{array}{l}\text { Complete } \\
\text { mechanical } \\
\text { obstruction }\end{array}$ & $\begin{array}{c}\text { Partial } \\
\text { mechanical } \\
\text { obstruction }\end{array}$ & \\
\hline Type of obstruction & $35(87.5 \%)$ & $5(12.5 \%)$ & $8(20 \%)$ & $32(80 \%)$ & \\
\hline Non-operative management & $34(97.5 \%)$ & $0(0 \%)$ & $0(0 \%)$ & $26(65 \%)$ & \\
\hline Operative management & $1 \quad(2.5 \%)$ & $5(100 \%)$ & $8(100 \%)$ & $6(15 \%)$ & \\
\hline Total operative rate in each group & \multicolumn{2}{|c|}{$6(15 \%)$} & \multicolumn{2}{|c|}{$14(35 \%)$} & 0.001 \\
\hline $\begin{array}{l}\text { Type of surgery: } \\
\text { Adhesiolysis } \\
\text { Strangulation \& resection }\end{array}$ & $\begin{array}{l}5 \\
1\end{array}$ & & $\begin{array}{l}11 \\
3\end{array}$ & & \\
\hline
\end{tabular}

Table (4): Resolution time \& hospital stay.

\begin{tabular}{llll}
\hline & $\begin{array}{c}\text { Gastrografin } \\
\text { group }\end{array}$ & $\begin{array}{c}\text { Control } \\
\text { group }\end{array}$ & $\begin{array}{c}p \text { - } \\
\text { value }\end{array}$ \\
\hline - Time of resolution in (h) & $18.8 \pm 21.6$ & $41.5 \pm 15.8$ & 0.001 \\
- Mean time of the hospital & 3.9 & 6.8 & 0.002 \\
$\begin{array}{l}\text { stay (days) } \\
\begin{array}{l}\text { The hospital stay in non- } \\
\text { operative patients (days) }\end{array}\end{array}$ & $3.2 \pm 1.5$ & $5.3 \pm 4.8$ & 0.04 \\
\hline
\end{tabular}

Table (5): Operative predication for ASBO after administration of gastrografin.

\begin{tabular}{lccc}
\hline Sensitivity $\%$ & Specificity $\%$ & PPV\% & NPV\% \\
\hline $83.3 \%$ & $100 \%$ & $100 \%$ & $97.41 \%$ \\
\hline
\end{tabular}

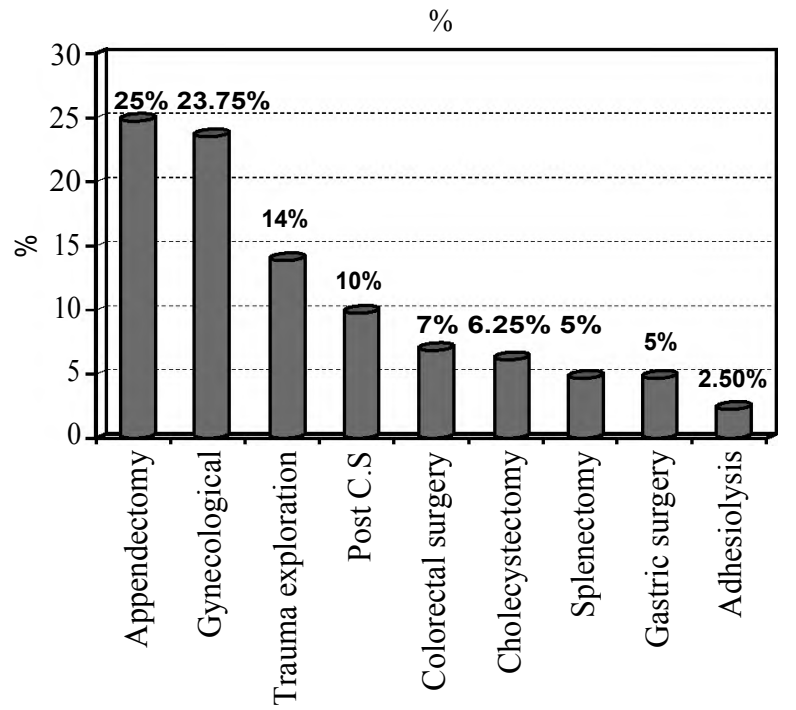

Fig. (1): Types of previous abdominal surgery.

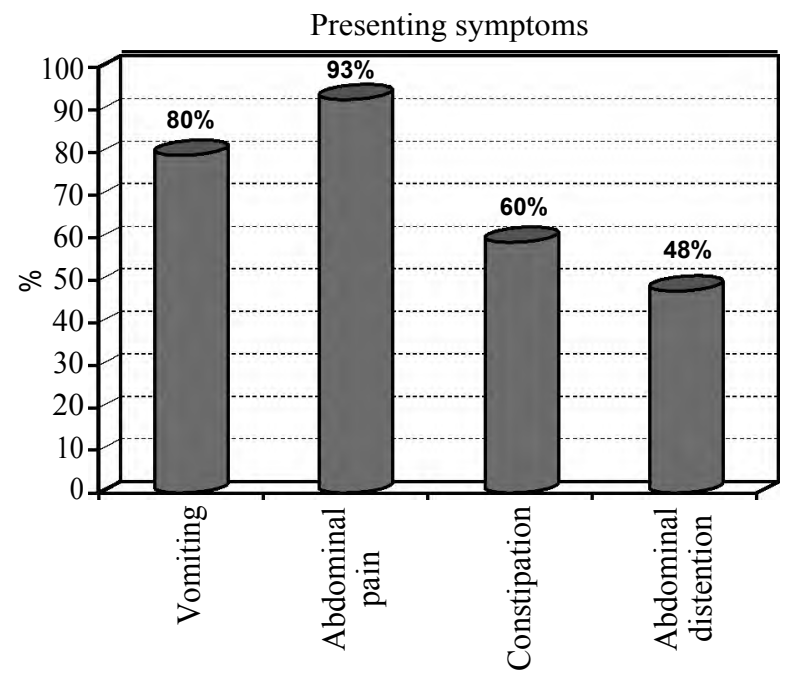

Fig. (2): Presenting symptoms.

\section{Discussion}

Intra-abdominal adhesions are likely the result of the inflammatory response to operative injury and infection. These adhesions represent the effect of the imbalance between fibrin deposition and degradation $[\mathbf{1 4 , 1 5}]$. Only minority of patients will develop symptoms of ASBO, while Intra-abdominal adhesions result in almost all patients after abdominal and pelvic operations [16].

The management of ASBO has remained controversial; most patients received trial of conservative treatment initially unless there was suspicion 
of strangulation. However, the optimal duration of conservative trial is not clear on safety and duration for ASBO [17]. The time allowed for conservative treatment before resorting to surgical intervention in patients with postoperative SBO still controversial. Some studies reported that non-operative management up to $5 \mathrm{~d}$ duration can be used safely for most patients [18], although some reports suggest a shorter period of 12,24 , or 48 to $72 \mathrm{~h}[\mathbf{1 9 , 2 0}$.

Gastrografin is the most common water-soluble contrast mediums to be used to evaluate postoperative adhesion obstruction, as it is non toxic in the peritoneal cavity [21]. Barium has also been used in evaluation of postoperative ASBO, but some authors suggest that barium may be dangerous in cases of nearly complete obstruction, as it may thicken upstream of the level of obstruction [19]

Considering the primary outcomes, in this study the use of gastrografin decreased operative rate from $35 \%$ in control group to $15 \%$ in gastrografin group. Surgery was needed in $100 \%$ of patients in whom contrast failed to reach the colon within $24 \mathrm{~h}$ and in $2.5 \%$ of patients in whom contrast reached the colon within $24 \mathrm{~h}$. Resolution of obstructive symptoms was earlier in patients given gastrografin. The hospital stay was shorter in gastrografin group (3.2d) than in control group (5.3d). This is probably because resolution of ASBO with Gastrografin is faster and patients can be fed more early than patients of control group according to the gradual return of bowel function usually practiced in traditional conservative management of ASBO, with mean time to resolution $(18.8 \pm 21.6 \mathrm{~h})$ in gastrografin group versus $(41.5 \pm 15.8 \mathrm{~h})$ in control group.

Diagnostic role of gastrografin and its therapeutic effect in ASBO have been investigated by several previous studies generating controversial results [22]. In the meta-analysis conducted by Abbas et al., it was reported that the passage of gastrografin in the colon within $24 \mathrm{~h}$ predict the resolution with a specificity of $96 \%$ and sensitivity of $97 \%$ [23] . In our study, the passages of gastrografin in the colon within $24 \mathrm{~h}$ predict the resolution with a specificity of $100 \%$ and sensitivity of $83.3 \%$.

Regarding the length of the hospital stay, the finding in our study is similar to that of previous studies which also showed that gastrografin treatment significantly reduced length of hospital stay [12]. One study, however, did not find any advantage in relation to the length of hospital stay [25] There were no adverse effects of gastrografin during the study, making it safe to use so long as caution is taken during its administration.
Regarding the operative rate, some previous studies have recorded no advantage of the use of gastrografin in reducing the need for surgery. Biondo et al., reported that water-soluble contrast reduced the hospital stay but did not reduce the need for surgery [25]. Other study conducted by Feigen et al., denied any advantage of gastrografin use in decreasing the operative rate in ASBO [24] However, Choi et al., reported that its use significantly reduced the need for surgery by $74 \%$ [26] Some studies which showed that gastrografin reduced the need for surgery, had bigger sample sizes; Di Severio et al., [22] and Assalia et al., showed that gastrografin reduced the need for surgery [27]. A recent study to consider an institutional management model for predicting the need for surgical exploration in cases of ASBO concluded that gastrografin decreased the need for exploration in patients not meeting the criteria for immediate operation [28].

In our study gastrografin use decreased the surgical rate from $35 \%$ in control group to $15 \%$ in gastrografin group. Surgical intervention was required in $100 \%$ of patients in whom contrast failed to reach the colon within $24 \mathrm{~h}$ and in $2.5 \%$ of patients in whom contrast reached the colon within $24 \mathrm{~h}$.

The rate of bowel strangulation in patients with ASBO ranged from $6 \%$ up to $11 \%$ in [4]. In this study, the strangulation rate was $5 \%$. In gastrografin group only one $(2.5 \%)$ patient versus three $(7.5 \%)$ in control group. There was no evidence that the use of gastrografin would increase the risk of bowel obstruction [12].

This study still has some limitations; the database did not include information regarding the severity of ASBO.

\section{Conclusion:}

Gastrografin is effective in management of ASBO as it helps in early resolution and shortens the hospital stay. It also, helps in early diagnosis of patients who require surgery and significantly reduces the requirement for surgical intervention in patients with partial ASBO.

\section{Financial support and sponsorship: Nil.}

\section{Conflicts of interest:}

There are no conflicts of interest.

\section{Acknowledgement:}

The authors wish to warmly thank Dr. Mohamed Rezk for his input in data analysis, and the doctors 
of General Surgery Department, Assiut University Hospital, Egypt.

\section{References}

1- MILLER G., BOMAN J., SHRIER I., et al.: Etiology of small bowel obstruction. Am. J. Surg., 180: 33-6, 2000.

2- GORE R.M., SILVERS R.I., THAKRAR K.H., WENZKE D.R., MEHTA U.K., NEWMARK G.M. and BERLIN J.W.: Bowel obstruction. Radiol. Clin. N. Am., 53 (6): 1225-40, 2015.

3- BAMPARAS G., BRANCO B.C., SCHÜRIGER B., LAM L., INABA K. and DEMETRIADES D.: The incidence and risk factors of post laparotomy adhesive small bowel obstruction. J. Gastrointest. Surg., 14: 1619-28, 2010.

4- Di SAVERIO S., COCCOLINI F., GALATI M., SMERIERI N., BIFFL W.L., ANSALONI L., TUGNOLI G., VELMAHOS G.C., SARTELLI M. and BENDINELLI C.: Bologna guidelines for diagnosis and management of Adhesive Small Bowel Obstruction (ASBO). World J. Emerg. Surg., 8: 42, 2013.

5- PARKER C., ELLIS H., MORAN B.J., et al.: Postoperative adhesions: Ten-year followup of 12,584 patients undergoing lower abdominal surgery. Dis. Colon. Rectum., 44: 822-30, 2001.

6- WECKBECKER G., LEWIS I., ALBERT R., et al.: Chemical agentsin prevention of adhesive intestinal obstruction. Nat. Rev. Drug. Discov., 2: 999-1017, 2003.

7- ELLIS: The magnitude of adhesion related problems. Ann. Chir. Gynaecol., 87: 9-11, 1998.

8- CHEN S.C., LIN F.Y., LEE P.H., et al.: Water soluble contrast study predicts the need for early surgery in adhesive small-bowel obstruction. Br. J. Surg., 85: 1692, 1998.

9- FEVANG B.T., JENSEN D. and FEVANG J.: Upper gastrointestinal contrast study in the management of small bowel obstruction a prospective randomized study. Eur. J. Surg., 166: 39, 2000.

10- BIONDO S., PARES D., MORA L., et al.: Randomized clinical study of gastrografin administration in patients with adhesive smallbowel obstruction. Br. J. Surg., 90: $542,2003$.

11- RUBIN D.C.: Certain of surgical operation carry out adhesive intestinal obstruction. Am. J. Physiol., 263: 85363, 1992.

12- ABBAS S., ABBAS S., BISSET I.P. and PARRY B.R.: Meta-analysis of oral water soluble contrast agent in the management of adhesive small bowel obstruction. Br. J. Surg., 94: 404, 2007.

13- COHEN S., HARRIS L.D. and LEVITAN R.: Readmission criteria in adhesive intestinal obstruction. Gastroenterology, 54: 72, 1968.
14-ARUNG W., MEURISSE M. and DETRY O.: Pathophysiology and Prevention of Postoperative Peritoneal Adhesions. World Journal of Gastroenterology, 17: 4545-53, 2011.

15-ATTARD J.P. and MacLEAN A.R.: Adhesive small bowel obstruction: Epidemiology, biology and prevention. Can. J. Surg., 50 (4): 291-300, 2007.

16- LIAKAKOS T., THOMAKOS N., FINE P.M., et al.: Peritoneal adhesions: Etiology, pathophysiology, and clinical significance. Recent advances in prevention and management. Dig. Surg., 18: 260-73, 2001.

17- VAKIL R., KALRA S., RAUL S., PALJOR Y. and JOSEPH S.: Role of water soluble contrast study in adhesive small bowel obstruction: A randomised controlled study. Indian J. Surg., 69: 47-51, 2007.

18- SEROR D., FEIGEN E., SZOLD A., et al.: How conservatively can postoperative small bowel obstruction be treated? Am. J. Surg., 165: 121, 1993.

19- BROLIN R.E., KRASNA M.J. and MAST B.A.: Use of tubes and radiographs in the management of small-bowel obstruction. Ann. Surg., 206: 126, 1987.

20- HOFSTETTER S.R.: Acute adhesive obstruction of the small intestine. Surg. Gynecol. Obstet., 152: 141, 1981.

21- CHEN S.C., CHANG K.J., LEE P.H., et al.: Oral gastrografin in post-operative small-bowel obstruction. World J. Surg., 23: 1051, 1999.

22- Di SAVERIO S., CATENA F., ANSALONI L., GAVIOLI M., VALENTINO M. and PINNA A.D.: Water soluble contrast medium (gastrografin) value in adhesive small intestine obstruction (ASIO). World J. Surg., 32 (10): 2293-304, 2008.

23- CHEN S.C., CHANG K.J., LEE P.H., et al.: Oral gastrografin in post-operative small-bowel obstruction. World J. Surg., 23: 1051, 1999.

24- FEIGEN E., SEROR D., SZOLD A., et al.: Water-soluble contrast medium has no therapeutic effect on postoperative small-bowel obstruction: Results of a prospective randomized clinical trial. Am. J. Surg., 171: 227, 1996.

25- MATTER I., KHALEMSKY L., ABRAHAMSON J., et al.: Does the index operation influence the course and outcome of adhesive intestinal obstruction? Eur. J. Surg., 163: 767, 1997.

26- CHOI H.K., LAW W.L., HO J.W. and CHU K.W.: Value of gastrografin in adhesive small bowel obstruction after unsuccessful conservative treatment: A prospective evaluation. World J. Gastroenterology, 11 (24): 3742-45, 2005.

27- ASSALIA A., KOPELMAN D. and BAHOUS H.: Gastrografin for mechanical partial, small bowel obstruction due to adhesions. Harefuah, 132: 629, 1997.

28- GOUSSOUS N., EIKEN P.W., BANNON M.P. and ZIELINSKI M.D.: Enhancement of a small bowel obstruction model using the Gastrografin ${ }^{\circledR}$ challenge test. J. Gastrointest. Surg., 17: 110-6, 2013. 


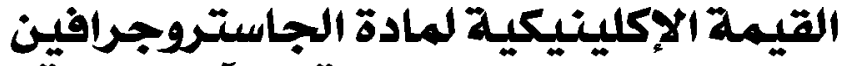

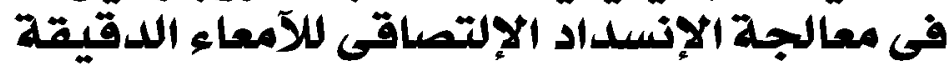

يعتبر الإنسداد المعوى الإلتصاقى من آهم المضاعفات التى تتبع الجراحات الباطنية. ويعتبر الإنسداد الإلتصاقى للآمعاء الدقيقة السبب

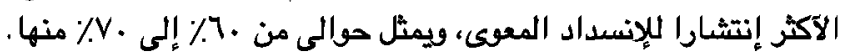

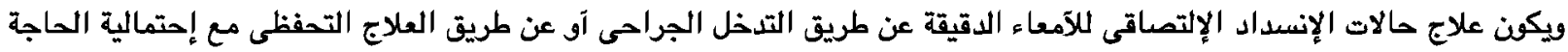

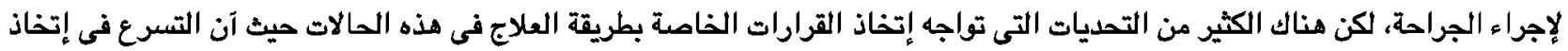

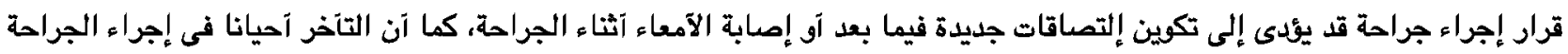

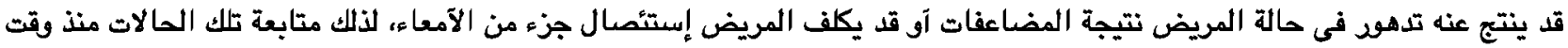

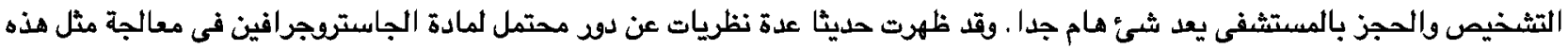

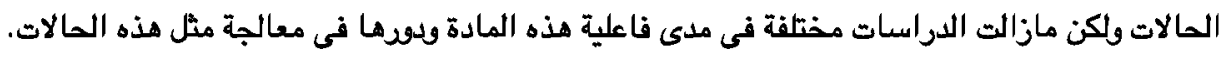

وتهدف هذه الدراسة إلى تقييم مدى مادة الجاستروجرافين فى تثخيص ومعالجة حالات الإنسداد الإلتصاقى للآمعاء الدقيقة.

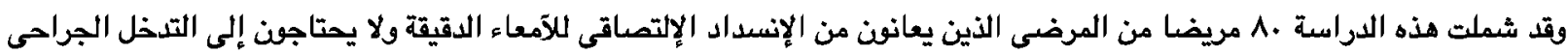

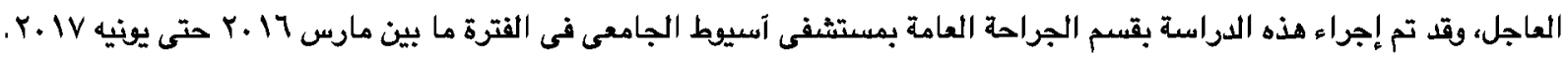

$$
\text { وقد تم تقسيم المرضى إلى مجموعتين: }
$$

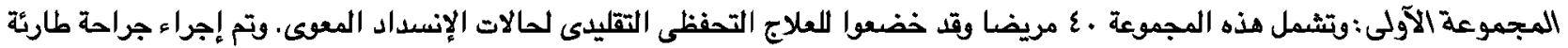

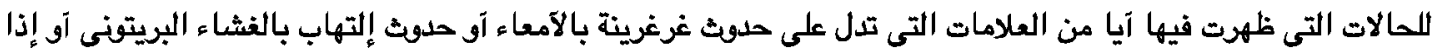

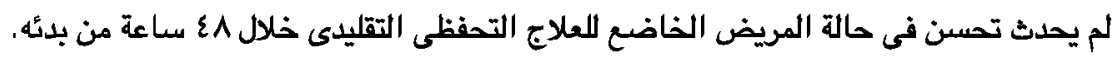

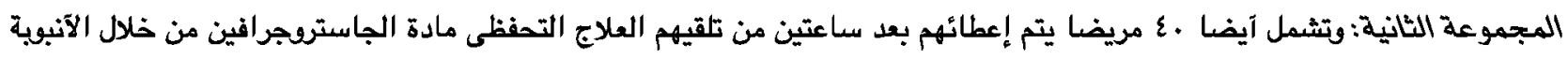

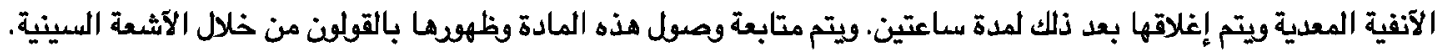

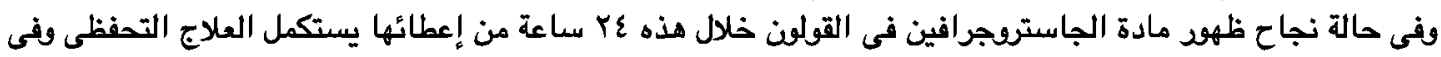

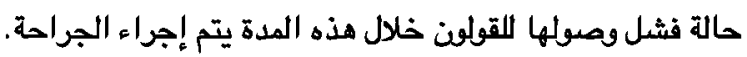

ووفقا لنتائج هذه الدراسة وققد وجد آن:

• الإنسداد الإلتصاقى للآمعاء الدقيقة قد يحدث بعد آيا من العمليات الجراحية الباطنية، ولكن يكن آكثر آكثر حدوثا بعد عمليات إستئصال الزائدة

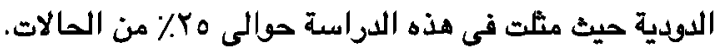

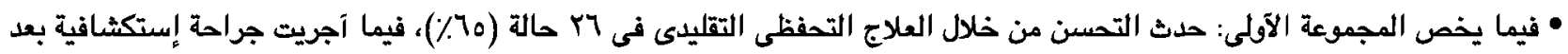

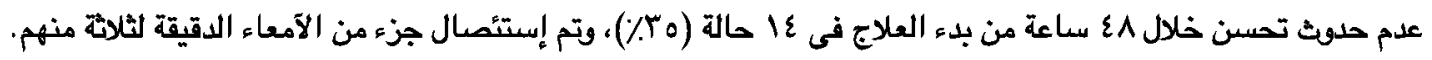

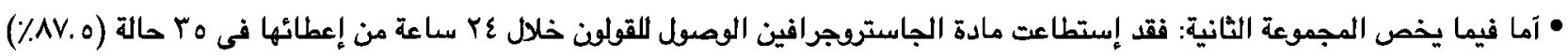

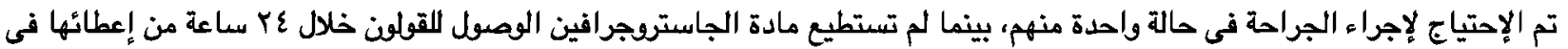

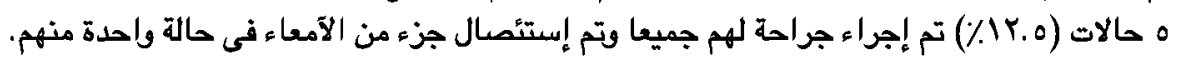

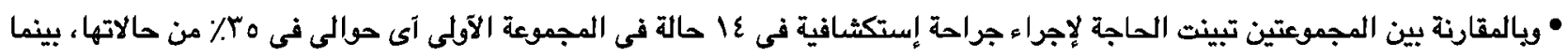

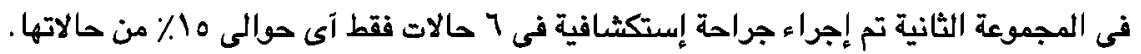

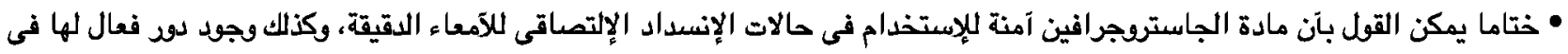
تشخيص ومعالجة مثل هذه الحالات والقدرة على تقليل الإحتياج لإجراء الجراحة وتقليل مدة الإقامة فئ الإنى المستشفى. 